
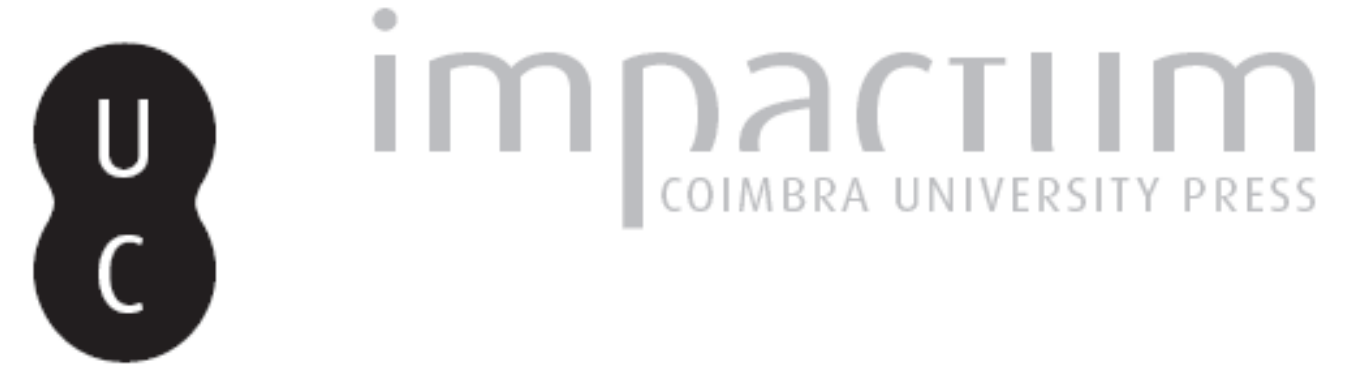

\title{
Grafitos, inscrição árabe e outras marcas históricas identificados no castelo de Montemor-o-Velho
}
Autor(es):
Penajoia, Marco
Publicado por: Centro de História da Sociedade e da Cultura
URL
persistente:
URI:http://hdl.handle.net/10316.2/39367
DOI:
DOI:http://dx.doi.org/10.14195/1645-2259_14_9
Accessed : $\quad$ 26-Apr-2023 13:55:28

A navegação consulta e descarregamento dos títulos inseridos nas Bibliotecas Digitais UC Digitalis, UC Pombalina e UC Impactum, pressupõem a aceitação plena e sem reservas dos Termos e Condições de Uso destas Bibliotecas Digitais, disponíveis em https://digitalis.uc.pt/pt-pt/termos.

Conforme exposto nos referidos Termos e Condições de Uso, o descarregamento de títulos de acesso restrito requer uma licença válida de autorização devendo o utilizador aceder ao(s) documento(s) a partir de um endereço de IP da instituição detentora da supramencionada licença.

Ao utilizador é apenas permitido o descarregamento para uso pessoal, pelo que o emprego do(s) título(s) descarregado(s) para outro fim, designadamente comercial, carece de autorização do respetivo autor ou editor da obra.

Na medida em que todas as obras da UC Digitalis se encontram protegidas pelo Código do Direito de Autor e Direitos Conexos e demais legislação aplicável, toda a cópia, parcial ou total, deste documento, nos casos em que é legalmente admitida, deverá conter ou fazer-se acompanhar por este aviso.

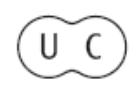




\section{4 \\ 2014}

\section{evista de História da Sociedade e da Cultura}

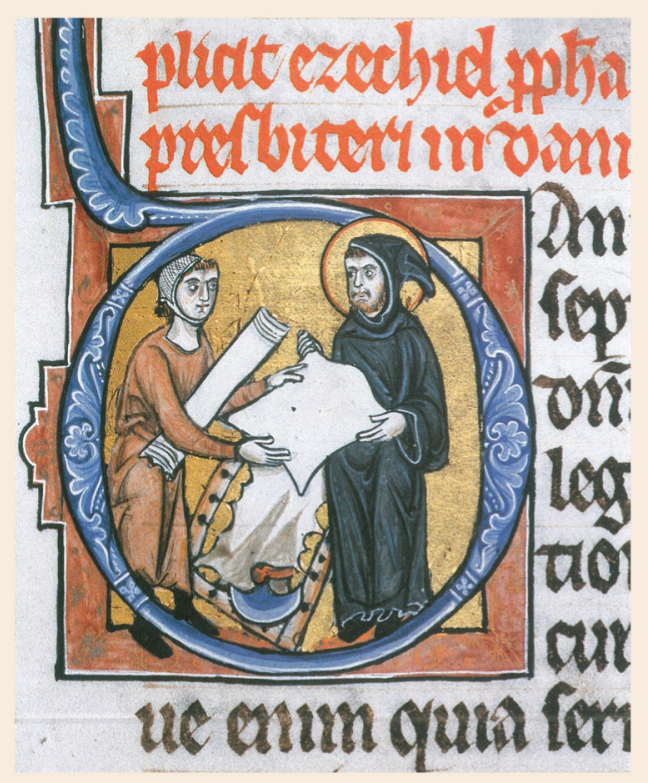

Centro de História da Sociedade e da Cultura Universidade de Coimbra 


\title{
Grafitos, inscrição árabe e outras marcas históricas identificados no castelo de Montemor-o-Velho
}

\author{
Marco Penajoia \\ Arqueólogo, Investigador Centro de História da Sociedade e da Cultura, \\ Universidade de Coimbra. \\ marco.penajoia@gmail.com \\ Texto recebido em/Text submitted on: 03.06.2014 \\ Texto aprovado em/Text approved on:04.10.2014
}

\section{Resumo/Abstract:}

No decurso de uma avaliação ao amuralhado de Montemor-o-Velho, surgiram vestígios de várias marcas históricas. Dentre os motivos esquemáticos identificados, enumeram-se os seguintes: grafitos de embarcação, figura humana, zoomorfo e formas geométricas (pentagramas). Marcas de canteiro e um cruciforme. É possível, também, demonstrar sinais de uma inscrição árabe.

Assim, o presente artigo pretende efetuar uma análise preliminar a estes traços históricos. Com estes vestígios agora identificados, estão lançados novos contributos para um melhor conhecimento sobre a dinâmica vivencial do castelo montemorense.

During an evaluation to the walls of Montemor-o-Velho appeared several traces of historical marks. The schematic patterns identified are: graffiti of ship, human figure, zoomorphic and geometric shapes (pentagrams). Signs of stonemason and a cruciform. It is also possible to show signs of an Arabic inscription.

Thus, this paper aims to provide a preliminary analysis of these historical traces. The identification of these remains allows a new contribution to a better understanding about the experiential dynamics of the Montemor castle.

Palavras chave/Keywords:

Castelo de Montemor-o-Velho; Grafitos; Embarcações; Inscrição árabe; Marcas históricas.

Montemor-o-Velho castle; Graffiti; ships; Arabic inscription; Historical marks. 
No período medieval, Montemor-o-Velho foi uma posição relevante nos avanços e recuos de uma fronteira, que se pretendia cristã, até se verificar a estabilização com a reconquista de Coimbra no ano de 1064.

São várias as obras que inserem Montemor e o Mondego numa dinâmica defensiva, comercial, social e cultural, cuja importância condicionou a hierarquização e distribuição dos povoados urbanos. Do mesmo modo, realçam o lugar de destaque que esta vila desempenhou nessa dinâmica, surgindo como um dos principais portos do reino, ao perpetuar a necessidade humana de alargar os horizontes, criando pontos de passagem de pessoas e bens. Usufruía de um excelente enquadramento geoestratégico, sob a proteção de uma elevação com fortaleza, e detendo uma fachada marítima, sendo que o seu porto era coadjuvado por vários eixos viários em ambas as margens do Mondego com acesso a Coimbra.

A partir desta contextualização, o presente artigo debruça-se sobre os resultados mais significativos de uma análise preliminar efetuada no amuralhado do castelo, que revelou: grafitos, outras marcas históricas (marcas de canteiro, um cruciforme, etc.) e uma inscrição árabe.

Relativamente ao termo grafito, este traduz uma técnica que implica uma gravação de traços de profundidade diminuta. Mário Barroca sintetiza bem este universo: "ao nível do suporte, pode ser registado sobre paredes, diretamente nos silhares ou nas argamassas, sobre afloramentos rochosos, em cerâmicas etc. ${ }^{1}$. De técnica, pode ser gravado, desenhado ou pintado. Quanto ao tema, este pode ser figurativo, ou apresentar texto" (BARROCA, 2000: 25, nota de rodapé 14, vol. I). Este tipo de gravação, apesar de ser uma prática ancestral ${ }^{2}$, demonstra na Europa uma atividade mais efetiva e qualitativa entre os séculos XIV e XVI (BRANCO; BILOU, 2011: 7). Estes registos parecem ser mais comuns, quer em quantidade, quer em qualidade, em estruturas de relativo gabarito monumental (caso de muralhas, torres, aquedutos e igrejas) (ibid.).

1 André Bazzana atesta o seguinte: "na maioria dos casos, os grafitos são incisões efetuadas numa superfície rígida e relativamente difícil” (BAZZANA, 2006: 21).

2 Remetemos para um artigo que apresenta um ponto de situação sobre esta matéria, nomeadamente a descrição de grafitos identificados nas ruínas romanas de Tróia (ENCARNAÇÃO et al., 2012). 
O primeiro grafito identificado (embarcação) está localizado na cisterna $^{3}$ do cercado norte do castelo, na parede externa norte, que está voltada para a atual Rua do Taipal (Fig. 1, ponto A e Fig. 2). Apresenta-se, aproximadamente, a 1,60 $\mathrm{m}$ do nível de circulação atual ${ }^{4}$.

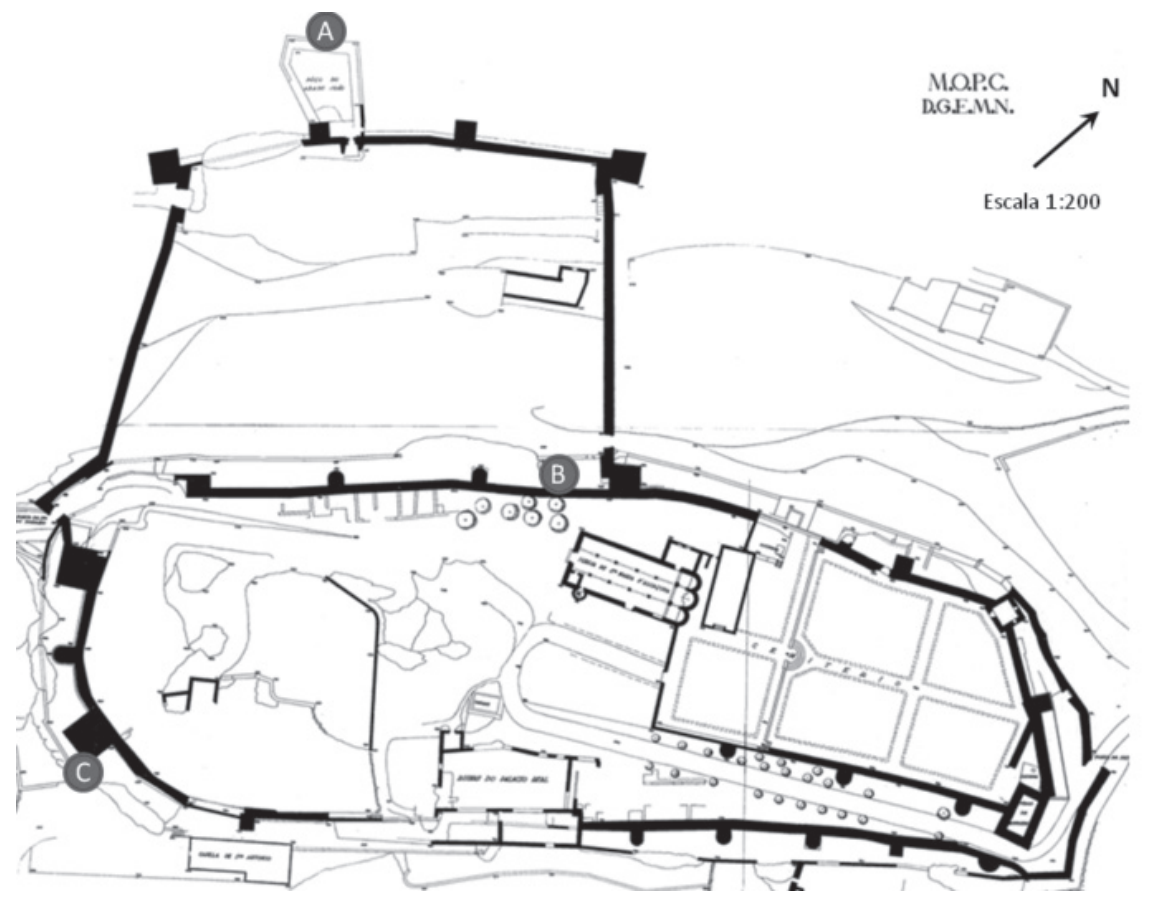

Fig. 1 - Planta do Castelo de Montemor-o-Velho anterior a 1949, com a posição dos conjuntos de grafitos (A e B), bem como da inscrição árabe (C). Adaptado de DGEMN, 1949.

A metodologia utilizada para a aquisição de todas as linhas desenhadas passou não só pela fotografia ortogonal, mas também pelo recurso, em ambiente noturno, de luz rasante com jogo de sombras apropriado. Ainda assim, registaram-se várias dificuldades, sobretudo ao nível da leitura de alguns traços. É o caso da fratura do lado esquerdo, que existe

3 Também conhecida como «Poço do Abade João».

4 Agradecemos ao Sr. José Couceiro a identificação deste grafito, à Dr. ${ }^{a}$ Sandra Lopes o alerta da existência do mesmo, bem como a toda a estrutura da Unidade de Cultura e Turismo da Câmara Municipal de Montemor-o-Velho, pelo incentivo ao seu estudo. 


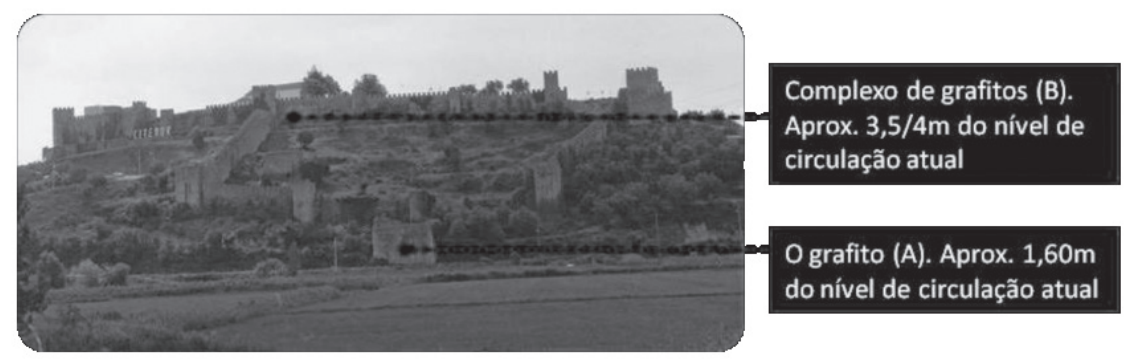

Fig. 2 - Localização dos grafitos: Cisterna do cercado norte ou «Poço do Abade João» (A); muralha superior voltada a NW (B).

na argamassa onde o grafito se estabelece e que interrompe a definição da embarcação. De notar que nem sempre o estado de conservação é o causador total das limitações de leitura destas marcas. Tomando a experiência dos levantamentos dos grafitos no baluarte de Denia, os investigadores notaram que "a imprecisão dos traços não se deve somente às capacidades criadoras dos seus autores, mas também à dificuldade técnica e material do suporte ou à inadaptação dos instrumentos utilizados" (BAZZANA; LAMBLIN, 1984: 76-77). Deste modo, foram efetuadas várias observações para evitar o menor número de perdas de linhas para o nosso registo.

Morfologicamente, este grafito caracteriza-se por ser uma embarcação com tipologia similar a uma barca medieval ${ }^{5}$ (Fig. 3). É composta por cerca de 26 linhas estilizadas/incisas, talvez com um pico $^{6}$. A largura dos traços varia entre os $0,3 \mathrm{~mm}$ e os $0,7 \mathrm{~mm}$ (é o caso de algumas zonas do mastro e do cordame). Relativamente à profundidade, esta ronda os 2 e os $5 \mathrm{~mm}$.

$\mathrm{O}$ barco grafitado sugere estar representado com a proa à direita, facultando deste modo uma narração no sentido da esquerda para a direita ${ }^{7}$, correspondendo à marcha da embarcação. Apresenta um mastro que está mais próximo da proa. O sistema de propulsão parece combinado por velas, uma

5 Segundo a análise preliminar do Prof. Doutor Vasco Gil Mantas, a quem agradecemos profundamente.

6 O feitor desta gravação poderia dispor de vários instrumentos, tais como: malhos; maços; ponteiros ou cinzéis; martelos; escopros; escodas; buril, entre outros (BARROCA, 2000: 122-126, Vol. I).

7 Situação análoga é verificada em determinadas embarcações grafitadas na igreja do mosteiro de St. ${ }^{a}$ Clara a Velha (Coimbra). Agradecemos ao Dr. Paulo César Santos (DRCC), pela informação da existência destas embarcações. 


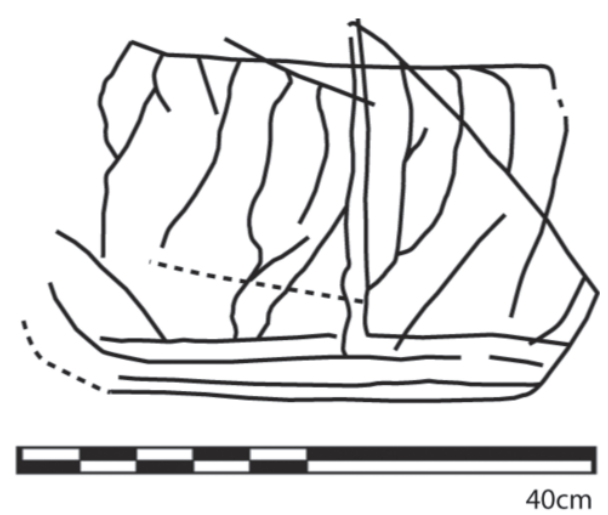

Fig. 3 - Desenho vetorial da embarcação grafitada na cisterna do cercado norte.

triangular e outra quadrada (aparelho redondo) ${ }^{8}$. O figurado dos dois tipos de velas poderá efetivamente corresponder ao mesmo grupo, ou evidenciar dois tipos de embarcação diferentes. A mesma hipótese poderá ser colocada relativamente ao casco. Vejam-se as linhas do mesmo: a meio observa-se uma linha que pode representar a divisão de dois cascos diferentes (demonstrando um palimpsesto de embarcações), ou então aludir simplesmente a uma linha de delimitação do tabuado, bem trincado, de um só barco. A complexidade das linhas desenhadas terá que, verdadeiramente, merecer graus de análise e de reflexão cuidadosos. Considerando a sua experiência de investigação em matérias semelhantes, André Bazzana adverte para o seguinte: “os traços sobrepõem-se, o que não é supreendente, já que podem ser de épocas diferentes, ou efetivamente não ser, pertencendo assim ao mesmo conjunto" (BAZZANA, 2006: 17) ${ }^{9}$. Quanto ao cordame, este está bem evidenciado, apresentando cerca de 15 linhas (Fig. 3).

8 A representação da vela redonda parece-nos clara. Quanto à triangular existem muitas dúvidas, pois esta forma pode simplesmente simbolizar parte do cordame.

Sobre esta questão e restante atividade náutica, veja-se o seguinte artigo: FONSECA, N; VACAS, T.; CASTRO Vieira de F. - Análise das características náuticas de embarcações latinas medievais in SOARES, C. Guedes e BRITO, V. Gonçalves de (ed.) - Inovação e desenvolvimento nas actividades maritimas. Lisboa: Edições Salamanca, 2006, p. 585-604.

9 Igualmente em Granada, podemos observar grafitos históricos com linhas incisas sobrepostas (BARRERA MATURANA, 2008: 156). Por sua vez, também existem gravações de barcos que efetivamente separam o casco em duas metades, uma superior e outra inferior, da proa à popa (ALONSO ROMERO, 1993: 266, embarcação A). 
No que concerne à argamassa constituinte da cisterna ${ }^{10}$, e onde o grafito está implantado, estamos a realizar uma análise comparativa ${ }^{11}$ com uma amostra da torre de menagem de Olivença ${ }^{12}$, cujo complexo de grafitos aí representado pode datar dos séculos XIV-XV (BARROCA, 2000: 26, Vol. I); (MARQUES, 2000: 15). Devemos salientar que se trata de estruturas de tipologia (cisterna e torre) e geografia (Montemor-o-Velho e Olivença) distintas. Ainda assim, esta análise poderá levantar questões pertinentes, nomeadamente na abordagem dos seguintes pontos: tipo de revestimento (assentamento ou reboco); proveniência dos materiais constituintes e comparação mineralógica; cronologia relativa. Poderá, portanto, servir de referência para outros estudos desse âmbito, inclusive de caráter interdisciplinar, onde se inclui a geologia.

O que terá motivado a execução deste grafito? Quem serão os autores? Que cronologia apontar? São estas questões que serão debatidas de seguida.

Como já foi abordado no início deste artigo, Montemor tinha uma apetência portuária de referência e o seu castelo poderia materializar no sector norte (onde se encontra a cisterna), uma das áreas portuárias (PENAJOIA, 2012).

Um primeiro ponto de análise passa por perceber o estado de conservação atual desta cisterna, e se realmente sofreu restauros significativos. Sabemos que, em 1936, o cercado norte foi alvo de reconstrução nos seus panos de muralha e que, em 1969, o "poço do Abade João" e muralhas próximas também foram alvo de reparação. Contudo, se observarmos uma fotografia de 1906 (Fig. 4), podemos verificar que a zona da cisterna se mantém

${ }^{10}$ Esta cisterna está protegida por duas torres, ladeadas por dois cubelos, onde se abrem duas portas de arco ogival e vários postigos, que davam para as almuinhas e campos contíguos (CONCEIÇÃO, 1944: 80).

Já existem estudos de barcos grafitados inseridos em cisternas ou masmorras (BAZZANA, 2006: 17).

A argamassa onde se inserem as embarcações islâmicas grafitadas em Alcácer do Sal é descrita como "militar" (COTTART; CARVALHO, 2010: 198).

${ }^{11}$ Análise a ser efetuada no Laboratório HERCULES, da Universidade de Évora, e no Laboratório de Geotecnia e Tratamento de Minérios, do Departamento de Ciências da Terra, da Faculdade de Ciências e Tecnologia da Universidade de Coimbra.

${ }^{12}$ Conforme visita técnica do Município de Montemor-o-Velho efetuada no dia 19 de Setembro de 2013. 


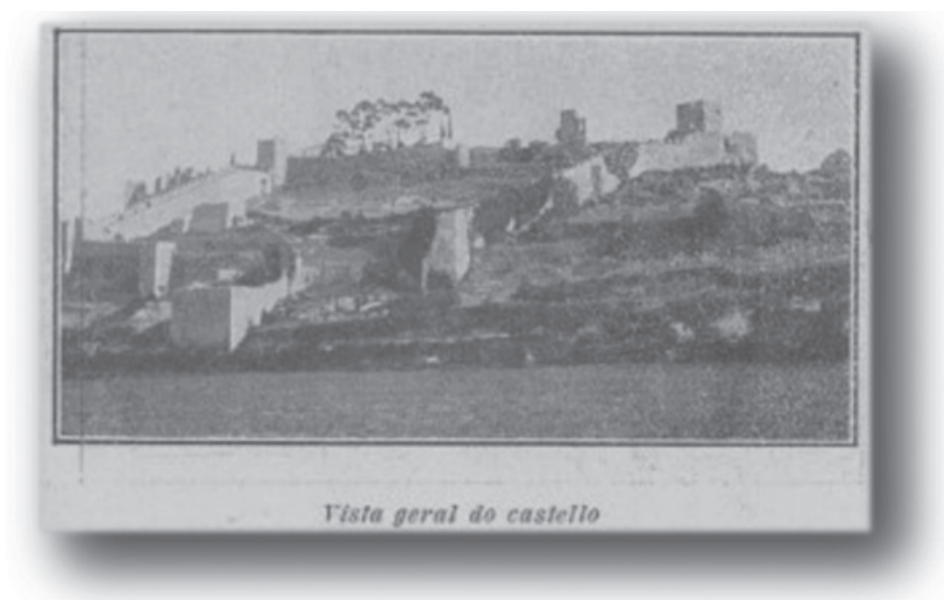

Fig. 4 - Estado da área do Cercado norte do castelo no ano de 1906 (FIGUEIREDO, 1906).

inalterada, ao contrário dos panos de muralha adjacentes, que se encontram em elevado estado de degradação.

Estes registos podem ter sido motivados por questões autorais associadas ao terminus e remate de construções de grande porte, ou simplesmente transmitir uma criação lúdica (BRANCO; BILOU, 2011: 7-8).

A presença deste grafito nesta área parece enquadrar-se no universo náutico, visto que "os grafitos representando embarcações aparecem sobretudo em lugares bem chegados à costa, quer no mundo islâmico quer no mundo cristão" (SOUTO, 1988: 470) ${ }^{13}$.

De realçar que a peregrinação para Santiago de Compostela, no séc. XI, passaria por Montemor, e muito provavelmente em torno do seu castelo, cujas partidas se fariam por via marítima ${ }^{14}$. Contudo, é aqui que reside

${ }^{13}$ Veja-se a intenção de gravação de embarcações em materiais cerâmicos que se relacionam com sítios de navegação ("encontramos barcos gravados que, por si só, nos remetem diretamente para o seu âmbito cultural, uma vez que se trata de tipos de embarcações usadas por navegantes fenícios"; VILAÇA, 2007: 14). Muito recentemente, no museu Dr. Santos Rocha (Figueira da Foz), foi identificado um fragmento cerâmico (proveniente da campanha de Santa Olaia - 1993), com sinais de uma embarcação grafitada (informação gentilmente cedida pelo Dr. José Franco). Já com estudo efetuado estão os grafitos islâmicos de embarcações em Alcácer do Sal, zona marcadamente náutica (COTTART; CARVALHO, 2010).

${ }^{14}$ Segundo as referências de Edrisi: "entre Coimbra y Santarém, del lado del Medio dia, hay três jornadas, y á doce millas al Poniente desemboca el rio Mondego, cerca del castillo de Montemayor, muy fuerte, com vistas al mar, feraces campinas y Buenos rendimentos. 
alguma problemática, porquanto aparecem vários grafitos de embarcações em zonas bem afastadas da dinâmica náutica, como por exemplo Olivença, na fronteira raiana (BARROCA, 2000: 26, Vol. I); (MARQUES, 2000), ou no castelo de Estremoz (BRANCO; BILOU, 2011: 8). Esta situação não impede que os gravadores destes barcos tenham estado em contacto com o universo flúvio-marítimo. É sobejamente conhecida a nossa ligação com culturas de índole náutica. Nesse sentido, e no que se concerne à população da região litoral de Coimbra, um estudo de genética demonstrou que as migrações provenientes das rotas marítimas do Mediterrâneo deixaram a sua "assinatura" na informação genética contida no cromossoma $Y$ (MARTINIANO et al. 2013). Sabemos que a empresa dos Descobrimentos e a Expansão galvanizaram todo o reino, e que grande parte da população procura o litoral no sentido de aproveitar novas oportunidades e meios de subsistência (MATTOSO, 1998: 18) ${ }^{15}$. Esta mobilização via-se também, de alguma forma, reforçada pelo espírito e entusiasmo associados à memória das antigas Cruzadas (SANTOS, 2004: 90). Portanto, muitos destes grafitos eram realizados a partir da recordação de indivíduos que frequentavam o mar, os estaleiros navais e os portos. Mesmo em zonas junto ao oceano, como é o caso de Denia, foram gravados barcos em sectores onde não se avistava o mar e o porto, cabendo ao gravador fazê-lo a partir da sua lembrança (BAZZANA; LAMBLIN, 1984: 78-79).

Uma particularidade do grafito em estudo passa por alguma similitude com o barco que está desenhado numa cartografia do rio Mondego ${ }^{16}$, e que

Si quieres hacer el viaje de Coimbra á Santiago por mar, saldrás del castillo de Montemayor (...) Mondego, que corre al O. Hacia el mar, y cuya desembocadura está defendida por el fuerte de Montemayor" (UBIETO ARTETA, 1974: 138;139;172).

${ }^{15} \mathrm{O}$ carácter marítimo do território português leva a que, muitas vezes, o lavrador vire pescador e vice-versa (DIAS, 2002: 279).

Em Denia, o "espírito de aventura, a vontade expansionista e dinâmica comercial, podem expressar as recordações ou nostalgias das gentes do mar" (BAZZANA; LAMBLIN, 1984: 19-20).

Já relativamente a Montemor, os seus forais demonstram a sua riqueza litorânea, como a pesca (barcas de pescadores), venda de pescado e de frutos do mar (COELHO, 2002: 17).

${ }^{16}$ Lixa Filgueiras, no seu zonamento das construções navais, indica para a região do entre Douro e a Estremadura: uma construção "homogénea e marcada por formas e técnicas referenciáveis ao Próximo Oriente” (FILGUEIRAS, 1965: 305).

De referir ainda algumas considerações sobre os sistemas primitivos de transporte no rio Mondego, efetuadas por Edgar Lameiras (LAMEIRAS, 1988). 


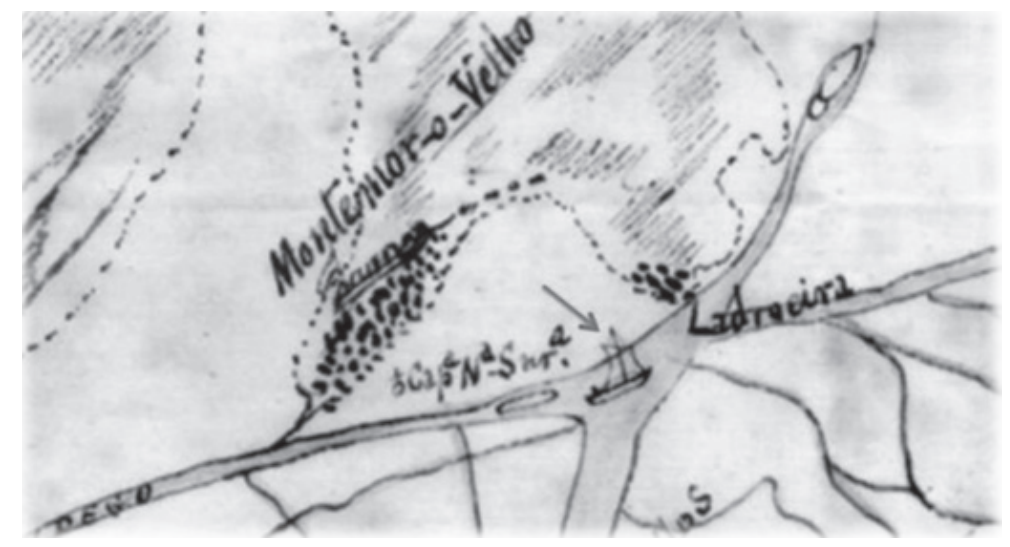

Fig. 5 - Planta do Rio Mondego, onde se pode observar uma embarcação a navegar em frente à posição do atual Casal Novo do Rio (Arquivo Municipal da Figueira da Foz, sem ano e autor).

navega junto a esta área, numa rota: Montemor - Casal Novo do Rio ${ }^{17}$ (PENAJOIA, 2012) (Fig. 5). Portanto, à partida, não seria uma embarcação de alto bordo. Estaria mais adaptada ao tráfego fluvial. Tal não significaria que não pudesse praticar navegação de cabotagem ao longo do litoral.

Ao nível cronológico, não nos é possível datar este grafito, visto que não dispomos de qualquer inscrição, assinatura oficial ou outro sinal específico de uma determinada época. Ainda assim, algumas características apontam, como já vimos, para o mundo medieval. Podemos hipoteticamente relacionar alguns vestígios arqueológicos, que se têm identificado na encosta do Monturo $^{18}$, e que se dispersam até à cisterna onde esta gravação se encontra. Estes materiais estão a ser alvo de um estudo pormenorizado, mas passam sobretudo por fragmentos cerâmicos, vidro e escória férrea, podendo enquadrar-se entre a Baixa Idade Média e a Época Moderna.

Outra referência enumera os "sistemas primitivos de transporte de carga a montante de Coimbra, que percorriam o Mondego: barca serrana, barco de palheiros, barco de passagem e barco trabalhador" in Atas do 1. ${ }^{\circ}$ Congresso sobre o Baixo Mondego, Região e Património, decorrido entre 26 de Maio e 29 de Julho de 1990, Coimbra, 1992: 37.

${ }^{17}$ Continuando esta orientação, a rota iria certamente almejar a urbe de Coimbra. Sabemos que, pelo ano de 1854, surge a notícia que dá conta da existência de períodos onde os barcos demoravam três dias de Montemor a Coimbra (AA. VV. 1854: 68).

${ }^{18}$ Topónimo antigo que, atualmente tem a designação de "Escadas do Dr. Baptista Loureiro" (CONCEIÇÃO, 1944: 172). 
Existe igualmente a possibilidade de este grafito ter sido executado num contexto religioso. Segundo o investigador Barrera Maturana, podem existir diferentes interpretações para o aparecimento de barcos gravados, das quais se salientam as seguintes: a proximidade à costa; a não proximidade ao mar, que pode ser justificada pela existência de marinheiros em cativeiro, ou de indivíduos que já se relacionaram com o mundo náutico; ex-votos para agradecer à divindade o salvamento dos perigos do mar; ou acontecimentos bélicos (BARRERA MATURANA, 2008: 160-161). São conhecidos "desenhos, símbolos ou caracteres de natureza religiosa que refletem as manifestações de exorcismo popular (...), sendo também de recordar a função dos grafitos de oferendas (ex-votos)" (BAZZANA, 2006: 17-18).

A este nível podemos contextualizar alguns grafitos gravados no Mosteiro de Santa Clara a Velha (Coimbra) ${ }^{19}$. Especificamente, é possível identificar diversas embarcações (Fig. 6) e um cavalo. Estas manifestações poderiam assim relacionar-se com o desejo por parte de "peregrinos" de que a viagem de promessa fosse bem sucedida ${ }^{20}$.

Neste contexto, a execução dos ex-votos enquadra-se cronologicamente na longa diacronia, perdurando até aos nossos dias. Veja-se, por exemplo, o culto ao mar que as gentes de Montemor ainda mantêm², por exemplo, nas povoações de Vila Nova da Barca, Santo Varão, Gatões e Tentúgal.

Nesta linha pode enquadrar-se também o complexo de grafitos, composto por uma figura humana, um zoomorfo e motivos geométricos (pentagramas) ${ }^{22}$, que se apresentam no paramento exterior da muralha superior $\mathrm{NW}^{23}$ (Fig. 1, ponto B; Fig. 2) e, curiosamente, se orientam para o mar (Fig. 7).

${ }^{19}$ No interior da igreja, nas paredes oeste, que dividem esta do coro, enquadradas nas naves norte e sul.

${ }^{20}$ Igualmente integrada no contexto religioso está a caravela pintada num arco quinhentista da antiga capela do Espírito Santo dos Mareantes em Sesimbra (SERRÃO; SERRÃO, 1978). Agradecemos esta informação à Dr. ${ }^{a}$ Helena Moura (DRCC).

${ }^{21}$ Representações em quadros, imagens de santos e barcas de madeira.

${ }^{22}$ Esta iconografia não é exclusiva do mundo cristão e islâmico, porquanto estes motivos se podem remeter à Idade do Bronze e serem interpretados como símbolos solares de caráter protetor (BARRERA MATURANA, 2008: 160).

${ }^{23}$ Os grafitos estão a sensivelmente 3,5/4 m do nível de circulação atual. De ressalvar que esta muralha também parece ter escapado às intervenções de restauro executadas pela DGEMN. Veja-se novamente a Fig. 4 relativa ao ano de 1906. 

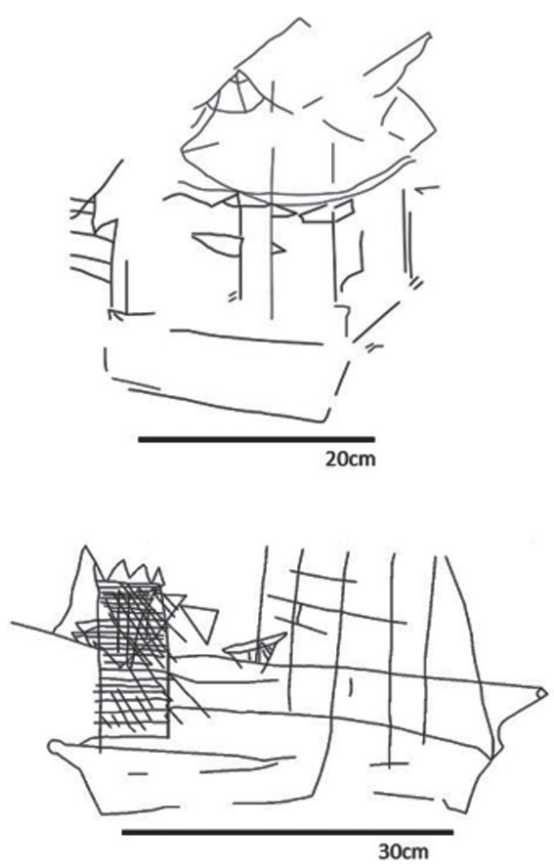
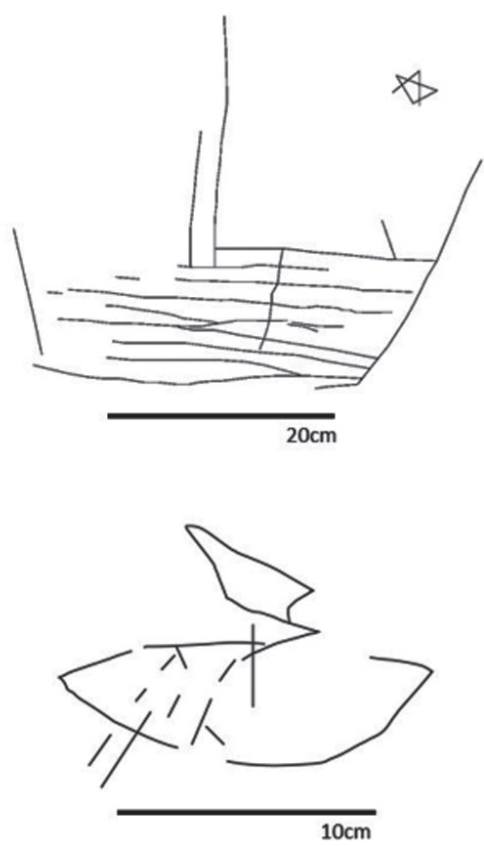

Fig. 6 - Traços gerais de algumas embarcações grafitadas no Mosteiro de Santa Clara-a-Velha (Coimbra).

Relativamente aos motivos geométricos, estando de frente para a muralha, observam-se quatro exemplares (Fig. 8). Por exemplo, os pentagramas n. ${ }^{\text {os }} 1$ e 4 parecem ter sido executados de uma forma contínua. Por sua vez, os n. ${ }^{\text {os }} 2$ e 3 , mostram evidências de terem sido efetuados por triangulações sobrepostas. Estes motivos medem cerca de $23 \mathrm{~cm}$ de altura e apresentam uma média de $20 \mathrm{~cm}$ de largura.

A este respeito, destacamos algumas posições geográficas detendo gravações destas marcas, nomeadamente em Denia (BAZZANA; LAMBLIN, 1984: 21) e Granada (BARRERA MATURANA, 2008: 159). Já em território nacional, estes motivos são identificados em variadas localizações, mormente em monumentos religiosos e militares. No Mosteiro de Santa Clara-a-Velha, bem próximo do nosso alvo de estudo, foi possível identificar um grafito de uma embarcação em associação com um pentagrama (Fig. 6, canto sup. drt.). O mesmo conjunto de representações também foi identificado no castelo de Arraiolos (BRANCO; BILOU, 2011). Estes símbolos também 


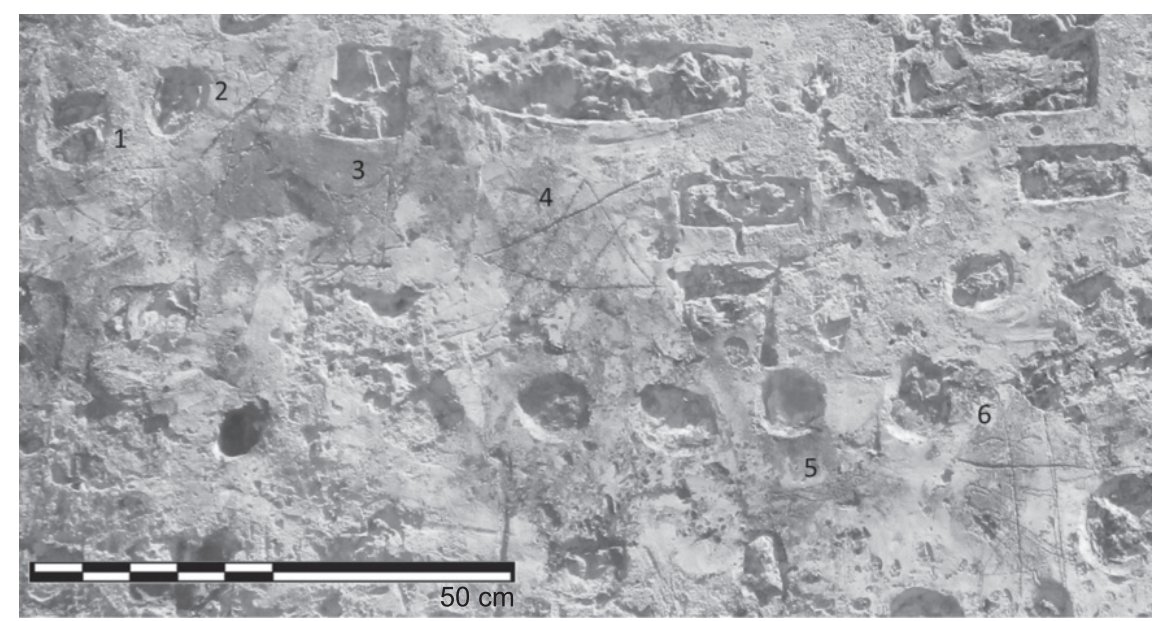

Fig. 7 - Localização do complexo de grafitos no paramento exterior da muralha superior NW (ponto B da planta do castelo).
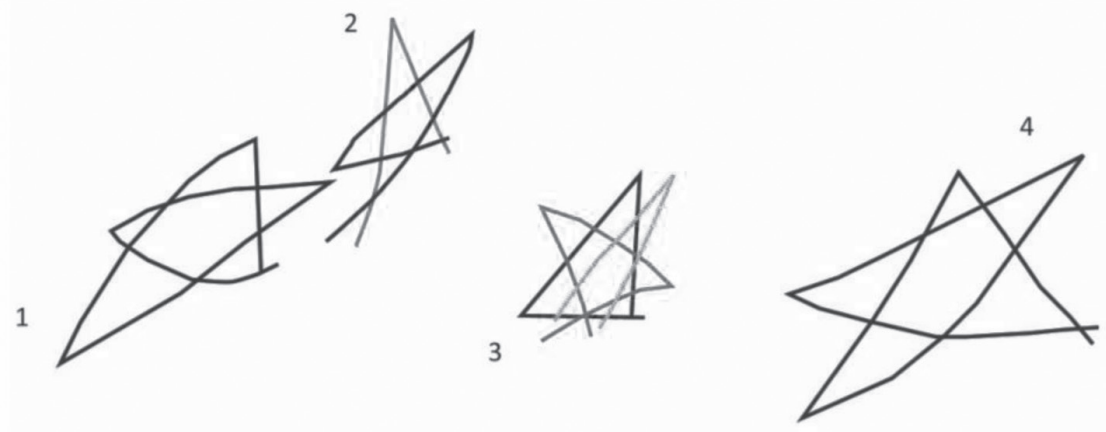

$30 \mathrm{~cm}$

Fig. 8 - Grafitos de motivos geométricos (pentagramas), localizados no ponto B da planta do castelo. Os motivos n. ${ }^{\text {os }} 2$ e 3 mostram evidências de terem sido efetuados por triangulações sobrepostas.

são observáveis no mundo piscatório, onde se podem salientar marcas de famílias piscatórias, ou sinalizar redes de pesca e outros objetos do seu quotidiano (GRAÇA, 1942; FILGUEIRAS, 1989). Juan A. Souto enquadra estes registos nos "signos mágicos", com uma componente ideológica que pode ser "mística, apotropaica e cosmológica ou corresponder a manifestações utilitárias, tais como calendários, jogos, esquemas gráficos para auxílio memorístico de artesão" (SOUTO, 1988: 470). Será talvez na 
vertente de signos protetore ${ }^{24}$, que os símbolos em questão se enquadram. Este investigador demonstra que todos os povos os utilizaram com a função de "amuletos ou talismãs que podem ser objeto de utilização pessoal. A sua missão é a de proteger um indivíduo, ou parte integrante do sistema decorativo de edifícios e complexos arquitetónicos, quando o seu feito consiste em proteger a estes e seus moradores" (ibid.).

Continuando a descrever este complexo de grafitos, realçamos agora os desenhos que se estabelecem na parte direita da muralha em questão, a cerca de 3,15 m do solo - um zoomorfo ${ }^{25}$ (n. ${ }^{\circ} 5$ ); uma figura humana e possíveis estandartes (n. ${ }^{\circ}$ ) (Fig. 9). Relativamente ao zoomorfo, este mede $17 \mathrm{~cm}$ de comprimento, 4 a $5 \mathrm{~cm}$ de altura e tem a cabeça voltada para a figura humana (lado direito) (Fig. 9).

Temos conhecimento da existência de gravações de animais neste castelo: veja-se a inscrição gótica do séc. XIII, no interior da igreja de Santa Maria de Alcáçova, que apresenta dois dragões (BARROCA, 2000: 1154, Vol. II, Tomo I). No que concerne à figura humana ${ }^{26}$ (Fig. 9), parece tratar-se de um guerreiro medieval, uma vez que se encontra caracterizado com vários adereços específicos de feição militar. Hipoteticamente, pode observar-se um "elmo", um escudo tendencialmente triangular ${ }^{27}$, uma espada embainhada e uma loriga ou cota de malha. Este grafito sugere uma ação de movimento, já que apresenta a perna direita esticada e a esquerda fletida. Acima do elmo, parece estar representada a figura de uma ave, que pode simplesmente ser o complemento habitual desta proteção - os penachos ou plumas $^{28}$. É observável que este desenho foi cortado por dois traços verticais

${ }^{24}$ Observem-se, por exemplo, os "signos protetores da fortificação islâmica de Gormaz (Soria): selos de Salomão, rosas bresa-pétalas, pentágonos, pentalfas, hexalfas" (SOUTO, 1988: 470). Os pentalfas registados no universo piscatório são descritos como símbolos de «São Selimão» (GRAÇA, 1942).

${ }^{25}$ Para além de barcos, é possível verificar "outros motivos navais, figuras humanas, zoomorfos, motivos vegetais, simbólicos ou geométricos (corações, estrelas, rosetas, cruzes (BARRERA MATURANA, 2008: 155).

${ }^{26}$ Mede sensivelmente $27 \mathrm{~cm}$ de altura e $19 \mathrm{~cm}$ de largura.

${ }^{27}$ Este escudo parece enquadrar-se na evolução que existiu a partir da segunda metade do século XII, onde passam a ser usados escudos mais pequenos e de formato tendencialmente triangular. Eram utilizados debaixo da axila direita do cavaleiro (MONTEIRO, 2006).

${ }^{28} \mathrm{O}$ "elmo" com estas características aparece genericamente na Península Ibérica, a partir de meados do século XIII (MONTEIRO, 2006). 

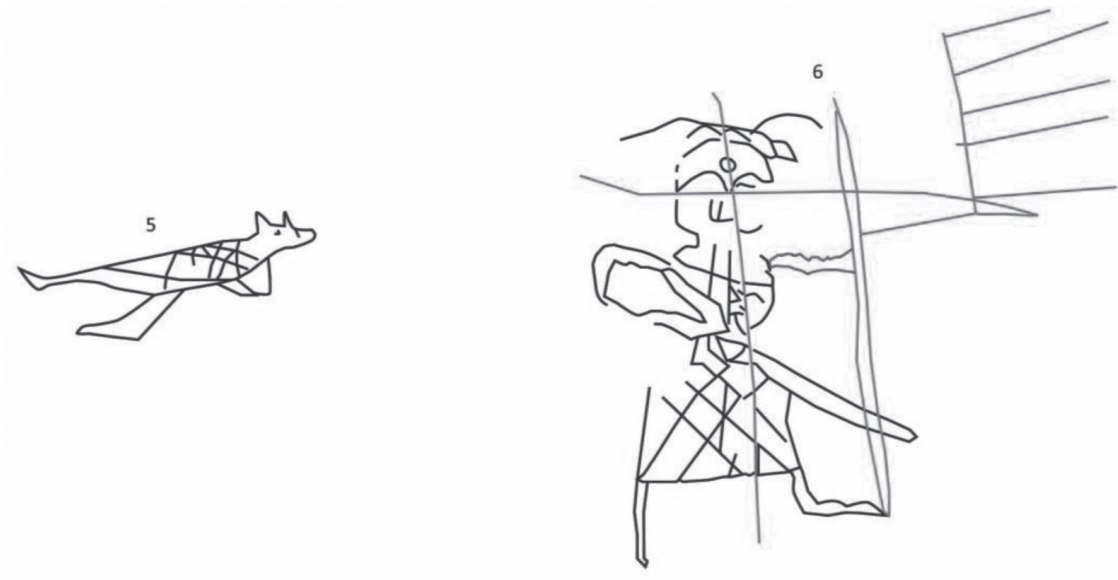

$30 \mathrm{~cm}$

Fig. 9 -. Desenho vetorial do grafito correspondente ao zoomorfo e à figura humana (feição militar). A cinzento, possível estandarte, ou riscos de contagem.

e um horizontal (a cinzento). Esta sobreposição à figura parece associar-se ao desenho de estandartes ou riscos de contagens (Fig. 9).

São de mencionar ainda, as marcas de canteiro identificadas no interior da igreja de Santa Maria de Alcáçova do Castelo $^{29}$ (Fig. 10, a; b), bem como no sexto degrau do adarve, que dá acesso à torre de menagem (lado SE) ${ }^{30}$ (Fig. 10, c); e o cruciforme ${ }^{31}$ marcado no adro da porta principal da mesma igreja (Fig. 10, e). Nesta medida, consideramos importante ressalvar a similitude que existe entre a marca do degrau e aquelas que estão gravadas numa das epígrafes ${ }^{32}$ e na laje da igreja de Santa Maria de Alcáçova

${ }^{29}$ É possível ainda verificar, no interior da igreja, um lajeado mais antigo, que se apresenta sobretudo na entrada principal e junto ao altar. Neste nível de circulação observamos marcações numéricas $(36 ; 7 ; 41)$ e também alguns fósseis.

${ }^{30}$ Neste patamar, observa-se a existência de várias pedras reaproveitadas devido ao seu talhe específico.

${ }^{31}$ É igualmente possível encontrar o termo cruzeiro para designar esta realidade, "por analogia com uma cruz de pedra, embora não tendo, decerto, o mesmo significado daquelas construções" (CANINAS et al., 2012: 316).

Como paralelo, veja-se o exemplo do levantamento de marcas de simbologia religiosa no núcleo urbano antigo de Estremoz. Aqui podemos observar a marca de uma cruz similar, que é descrita da seguinte forma: "cruz de base triangular, braços e topo simples" (SANTOS et al., 2000).

${ }^{32}$ Epígrafe seiscentista que se encontra na parede norte da igreja. 


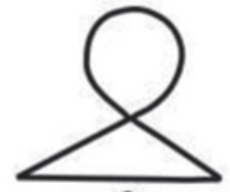

a

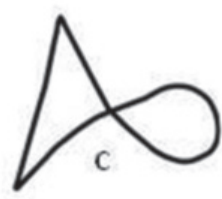

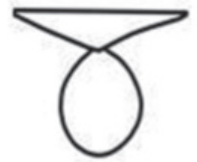

b
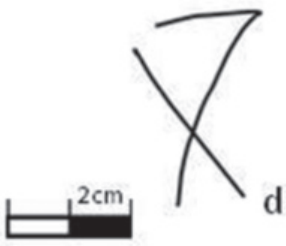
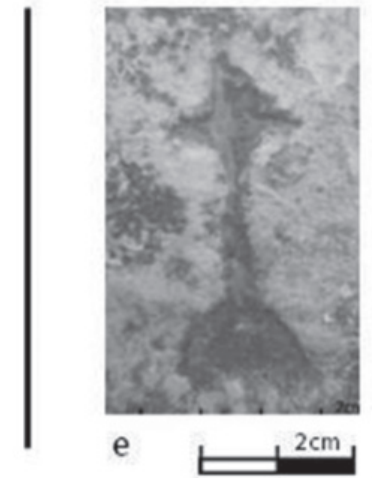

Fig. 10 - Marcas de canteiro e cruciforme: a - interior da igreja de Santa Maria de Alcáçova; $\mathrm{b}$ - representada na epígrafe seiscentista da mesma igreja; $\mathrm{c}$ - no sexto degrau do adarve que dá acesso à torre de menagem; $\mathrm{d}$ - Epígrafe moçárabe no exterior da parede Sul da igreja; e - cruciforme no adro da igreja.

(Fig. 10, b; c). Esta semelhança pode demonstrar que poderá ter sido o mesmo indivíduo a efetuar o talhe, no sentido de quantificar o seu trabalho, ou simplesmente aludir a uma forma de comunicação (religiosa, mágica, sinal de pertença ${ }^{33}$. Na inscrição funerária de Eugénia, do século XII (com influências moçárabes ${ }^{34}$ ), que se encontra na parede exterior junto à porta lateral da igreja (BARROCA, 2000: 151, Vol. II, Tomo I), podemos também identificar uma possível marca de canteiro (Fig. 10, d). A sua simbologia aparece em diversas cronologias e domínios, um dos quais o náutico. Neste âmbito, Santos Graça descreve um símbolo semelhante como "cálice emborcado" (GRAÇA, 1942).

Seguindo o pensamento de Octávio Lixa Filgueiras, devem multiplicar-se os estudos de Etnologia e Arqueologia naval, de uma forma estrutural (FILGUEIRAS, 1958: 11). Quando tratamos estes motivos como objetos meramente funcionais e técnicos, desvalorizamos todos os pluralismos que a 2013.

${ }^{33}$ Sobre esta questão, veja-se: CHARRÉU, 1997: 136; COIXÃO, 2002 e ROSAS et al.,

${ }^{34}$ De referir que Montemor teria sido, até aos finais do séc. XII, um importante atelier epigráfico com influências moçárabes (BARROCA, 2000: 170-172, Vol. I). 
história reserva. Nesse campo, incluem-se nomeadamente especificidades de um determinado território, que é "ocupado por comunidades de marinheiros, pescadores com as suas práticas sociais, culturais e religiosas específicas" (RIETH, 2013: 10).

Já no final desta análise arqueológica ao amuralhado de Montemor-o-Velho, foi possível ainda sinalizar um elemento de elevada importância arqueológica, dada a sua especificidade e raridade. Trata-se de uma inscrição $a_{\text {áabe }}^{35}$ (Fig. 11), já com um grau de erosão elevado ${ }^{36}$. Enquadra-se num silhar pertencente ao aparelho de frontaria, colocado no cunhal da segunda torre quadrangular de apoio à Porta de N. ${ }^{a}$ S. ${ }^{a}$ do Rosário/Sol. (Fig. 1, ponto C). Estabelece-se a 4,55 m de altura do solo e mede cerca de 1,10 m de comprimento e $40 \mathrm{~cm}$ de altura ${ }^{37}$. Observa-se que os caracteres foram escritos da direita para a esquerda (característica cultural do universo árabe), deixando para a extremidade superior esquerda uma possível marca que ainda está a ser estudada. Numa leitura preliminar, com todas as dificuldades associadas, a proposta da Prof. ${ }^{a}$ Doutora M. ${ }^{a}$ Antónia Martínez Núñez ${ }^{38}$, vai no sentido de podermos estar diante da frase:

A tradução para português aproxima-se do seguinte: "Isto foi escrito por $A s ̦ n \bar{a}$ '(ou $A d \underline{d} y \bar{a}$ ') '. Para realizar esta leitura, a investigadora identifica o verbo kataba (escrever) a remeter para uma ação passada, seguido do nome do sujeito do género masculino. De ressalvar que este tipo de frase é característico dos grafitos árabes de todas as cronologias.

${ }^{35}$ Identificação efetuada no dia 20 de Julho de 2014 entre as 15 e 17 horas, com o especial apoio de Marta Furtado.

Devido ao facto de esta descoberta ser recente, bem como às dificuldades impostas pela especificidade deste alfabeto, estamos a reunir condições técnicas para que seja possível apurar todos os detalhes.

${ }^{36} \mathrm{O}$ ângulo de incidência dos raios solares sobre o silhar foi determinante para a sua revelação.

${ }^{37}$ Esta torre tem uma altura estimada de $9 \mathrm{~m}$ (até à extremidade das ameias).

${ }^{38}$ Agradecemos o valioso préstimo da Prof. ${ }^{a}$ Doutora M. ${ }^{a}$ Antónia Martínez Núñez (Diretora do Departamento de Filologia Grega, Estudos Árabes, Linguística Geral e Documentação - Universidade de Málaga). Um agradecimento especial à Doutora Susana Gómez Martínez (Campo Arqueológico de Mértola / CEAACP-FLUC) e à Prof. ${ }^{a}$ Doutora Helena Catarino (FLUC-CEAACP), pela colaboração. O apoio prestado pelo Doutor Mohammed Nadir (FLUC) e pelo Prof. Doutor António Dias Farinha (FLUL), merece igualmente o nosso agradecimento. 


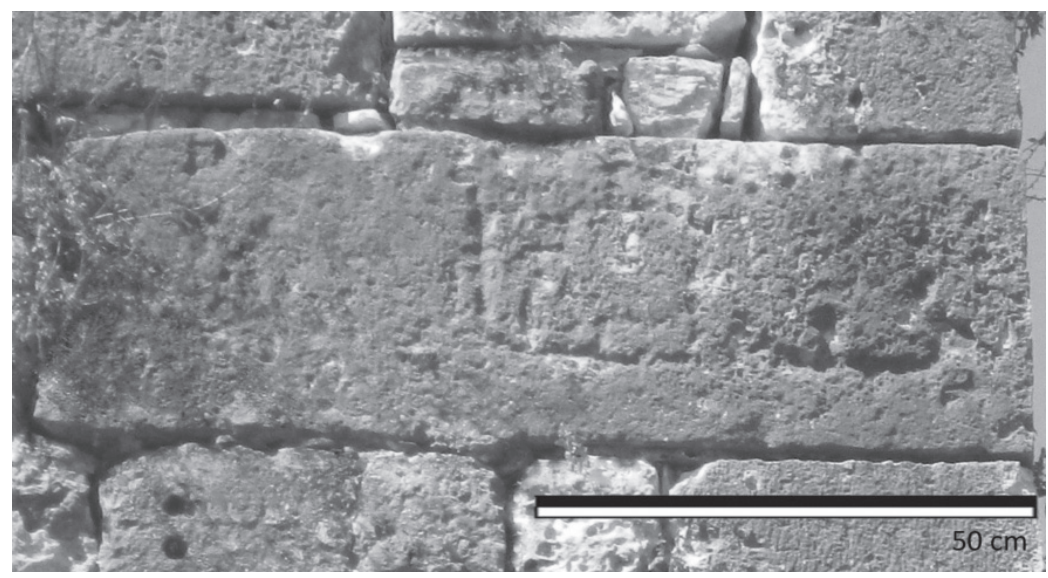

Fig. 11 - Inscrição árabe, identificada numa das torres quadrangulares (ponto C da planta do castelo).

Este torreão voltado a sul teria uma importância estratégica relevante, não só para os campos e controlo do rio Mondego, mas também para o burgo extramuros. Atendendo à sua posição, surgem-nos as mesmas questões pertinentes colocadas pelos investigadores dos grafitos de Alcácer do Sal (COTTART; CARVALHO, 2010:197-198). Serviria esta inscrição para conservar viva a cultura islâmica? Será o seu mau estado de conservação exclusivo de causas naturais, ou terá sido causado propositadamente? Haverá um cariz oficial?

Sabemos que em período de dominação muçulmana ${ }^{39}$, esta fortificação seria uma das mais importantes da Marca Inferior. A sua presença em Montemor, numa primeira fase, estabeleceu-se entre os anos 715-17 e 878; numa segunda fase, com as campanhas de al-Mansur em 990 ou 991, fase que se prolongou até 1064; por fim, durante as investidas que se fizeram sentir nos campos do Mondego entre 1116 e 1117 (BARROCA, 2005).

Teremos, assim, um ponto de partida para um hipotético quadro cronológico onde esta inscrição árabe se poderá enquadrar.

Concluindo, não podemos deixar de referir a razoável preservação deste conjunto de marcas. Se, por um lado, a argamassa onde se estabelecem os grafitos é de boa qualidade, por outro, temos agentes erosivos de grau

\footnotetext{
${ }^{39}$ Sobre a arqueologia do período islâmico em Portugal, veja-se: (CATARINO, 1995-1997).
} 
acentuado, nomeadamente o Sol, que vai reduzindo a qualidade destes registos. Aliás, é bem patente a fragmentação que a argamassa sofreu na zona mais central da muralha, onde se estabelece o conjunto B. No mesmo troço da muralha, entre os dois cubelos semi-circulares, existe uma concentração de plantas trepadeiras (heras), que está a ocultar e a deteriorar o aparelho de construção.

Relativamente à inscrição árabe, trata-se de um vestígio arqueológico de relevo, já que é o primeiro nesta linha a ser identificado, vindo assim reforçar a presença muçulmana ${ }^{40} \mathrm{em}$ Montemor-o-Velho.

Atendendo à importância destes vestígios no amuralhado, é premente articular medidas de minimização para a conservação e preservação deste património. Por agora ficam sinalizados todos estes registos, para que eventuais intervenções de restauro ou outras os possam respeitar.

Com estes novos dados que agora publicamos, estamos certos do enriquecimento patrimonial que irá beneficiar este baluarte. Pretendemos, com esta investigação, continuar a alcançar novos interesses de estudo, renovar outros e, sobretudo, atualizar o conhecimento histórico já produzido.

\section{Bibliografia}

AA.VV. - Breves reflexões históricas sobre a navegação do Mondego, e cultura dos campos de Coimbra. O Instituto, Jornal Scientifico e Litterario. Coimbra: Imprensa da Universidade de Coimbra. Vol. II (1854) 68-70; 78-80.

ALONSO ROMERO, F. - Los testemonios más antíguos de los medios de navegación entre el Mediterráneo y el Atlántico: Las embarcaciones de juncos en arte rupestre de Península Ibérica. Mediterrâneo. 2 (1993) 265-284.

ARTETA, Antonio Ubieto - IDRISI - Geografia de España. Textos medievais, 37 Valencia: Anubar (Cronista Almela y Vives), 1974.

\footnotetext{
${ }^{40}$ Atendendo à escassez destes artefactos nesta região, não podemos deixar de mencionar a inscrição árabe existente na Sé Velha, em Coimbra.
} 
BARRERA MATURANA, J.I. - Iconografia marginal: graffitos historicos en la casa nazari de calle Buenaventura, 2 (Granada). De Arte. 7 (2008) 153-166.

BARROCA, Mário Jorge - Epigrafia medieval portuguesa: 862-1422., 3 vol. em 4 tomos (Textos universitários de ciências sociais e humanas). Lisboa: Fundação Calouste Gulbenkian, 2000.

BARROCA, Mário Jorge - O Castelo de Montemor-o-Velho nos séculos X a XIII. Muçulmanos e cristãos entre o Tejo e o Douro (Sécs. VIII a XIII): actas dos seminários realizados em Palmela, 14 e 15 de Fevereiro de 2003; Porto, 4 e 5 de Abril de 2003. Coord. de Mário Jorge Barroca e Isabel Cristina Ferreira Fernandes. Palmela; Porto: Câmara Municipal de Palmela; Faculdade de Letras da Universidade do Porto, 2005, p. 111-126.

BAZZANA, André e LAMBLIN, M.P (ed.) - Los graffiti médiévales des Castell de Dénia. Catálogo. Dénia: Publicaciónes Museo Arqueológico, 1984.

BAZZANA, André - Les graffiti de bateaux dans al-Andalus et au Maghreb al-Aqsâ. Les Cahiers de l'Urbanisme. Mélanges d'archéologie médiévale, Liber amicorum en hommage à André Matthys. Hors série (2006) 16-34. BRANCO, Manuel J. C. e BIlOU, Francisco (ed.) - Inscrição e grafitos medievais no castelo de Arraiolos. Arraiolos: Câmara Municipal, 2011. CANINAS, João Carlos; HENRIQUES, Francisco; BATISTA, Álvaro; MONTEIRO, Mário - Casos de grafismos rupestres em calcários no centro de Portugal. 1. ${ }^{a}$ Mesa Redonda: Artes Rupestres da Pré-história e da Protohistória: Paradigmas e Metodologias de Registo. Trabalhos de Arqueologia: 54. Lisboa: Direcção-Geral do Património Cultural, 2012, p. 313-327.

CATARINO, Helena - Arqueologia do período islâmico em Portugal: breve prespectiva. O Arqueólogo Português, série IV, 13/15 (1995-1997) 457-484.

CHARRÉU, Leonardo - Siglas medievais de Estremoz: apontamentos de gliptografia medieval portuguesa. al-madan. 6, 2. a série (1997) 132-138. COELHO, Maria Helena da Cruz-Forais de Montemor-o-Velho. Montemor-o-Velho: Câmara Municipal, 2002.

COIXÃO, Sá - Siglas medievais de Vila Nova de Foz Côa. Côavisão cultura e ciência. 4 (2002) 43-55. 
CONCEIÇÃO, A. Santos - Terras de Montemor-o-Velho. Coimbra: Edição do autor, 1944.

COTTART, Nicole Danièle e CARVALHO, António Rafael - Os grafitos da muralha Amóada de Alcácer do Sal. Conimbriga. XLIX (2010) 183-223.

CHRISTIE, A. H. - Artes menores del Islam y su influencia sobre el trabajo en Europa in ARNOLD, Thomas e GUILLAUME, Alfred (ed.) - El Legado del Islam. Universidad Oxford; Madrid: Ediciones Pegaso, 1947, p. 139-197.

DIAS, Geraldo Coelho - O mar e os portos como catalisador de religiosidade. O Litoral em prespectiva histórica (séc. XVI-XVIII): Actas. FLUP, Porto: Instituto de História Moderna-Centro Leonardo Coimbra, 2002, p. 275-283.

ENCARNAÇÃO, José d’; PINTO, Inês Vaz; MAGALHÃES, Ana Patrícia e BRUM, Patrícia - A Epígrafe Latina Como Elemento Didáctico (XXXI): Escrever nas paredes... Boletim de Estudos Clássicos, Vol. 57 (2012) 51-57.

FIGUEIREDO, António Mesquita de - Montemor-o-Velho. Ilustração Portuguesa. 4, II série (1906) 101-104.

FILGUEIRAS, Octávio Lixa - A arte da construção no estudo das tradições navais. Separata de Studium Generale, Vol. V, Porto, 1958.

FILGUEIRAS, Octávio Lixa - Construções Navais Portuguesas. Actas do $V$ colóquio Internacional de Estudos Luso-Brasileiros, Coimbra: UC, 1965, Vol. I, p. 305-332.

FILGUEIRAS, Octávio Lixa - O barco poveiro - tentativas de decifração filo-genética. Póvoa de Varzim Boletim Cultural. 2, Vol. XXVI (1989) 433-466.

FONSECA, N; VACAS, T. e CASTRO Vieira de F. - Análise das características náuticas de embarcações latinas medievais in SOARES, C. Guedes e BRITO, V. Gonçalves de (ed.) - Inovação e desenvolvimento nas actividades maritimas. Lisboa: Edições Salamanca, 2006, p. 585-604. GRAÇA, António dos Santos - Inscrições Tumulares por Siglas. Póvoa de Varzim: Edição do autor, 1942.

LAMEIRAS, Edgar - Contributo para o estudo da navegação comercial e dos sistemas primitivos de transporte de carga do Rio Mondego a montante de Coimbra. Antropologia Portuguesa. 6 (1988) 81-107. 
LAMEIRAS, Edgar e BANDEIRA, José - As barcas serranas e a navegação comercial do rio Mondego. Baixo Mondego região e património: Actas do 1. ${ }^{\circ}$ Congresso, 1990, Coimbra: GAAC, LACAM, ADPCNS, ADPCP, AF, ADRL, ADCRP, 1992, p. 37-62.

MARQUES, Alfredo Pinheiro - Inscrições Medievais no Castelo de Olivença: Deixadas por mãos portuguesas na Torre de Menagem do Século XIV aumentada pelo "Príncipe Perfeito" Dom João II. Montemor-o-Velho: Centro de Estudos do Mar, 2000.

MARTÍNEZ NÚÑEZ, M. ${ }^{\mathrm{a}}$ A. - Epígrafia árabe e historia de al-Andalus: nuevos hallazgos y datos. Xelb 9: Actas do 6. ${ }^{\circ}$ Encontro de Arqueologia do Algarve. (2009) 39-53.

MARTINIANO, R.; FEITOSA, Y.; ABADE, A. e MANCO, L. - Y-chromo9some diversity in central Portugal reveals signatures of ancient maritime expansions. Anthropologischer Anzeiger-Journal of Biological and Clinical Anthropology. 70, 4 (2013) 355-367.

MATTOSO, José - Antecedentes Medievais da Expansão Portuguesa in BETHENCOURT, Francisco e CHAUDHURI, Kirti (ed.) - História da Expansão Portuguesa. Lisboa: Círculo de Leitores, Vol.I, 1998, p. 12-25. MONTEIRO, João Gouveia - Fontes e Métodos da História Militar. Programa, Conteúdos e Métodos de ensino. Vol. I (Texto, 325 pgs.). Vol. II (Anexo: Iconografia, 98 pgs). Relatório da disciplina apresentado a concurso para obtenção da categoria de Professor Associado do 5. ${ }^{\circ}$ Grupo (História). Faculdade de Letras, Coimbra, 2006.

PENAJOIA, Marco - A Questão portuária em torno de Montemor-o-Velho: Estudo de Arqueologia. Colecção Memória e Identidade, Montemor-o-Velho: Câmara Municipal, 2012.

RIETH, Eric - Octávio Lixa Filgueiras: um antropólogo de arquitectura naval de vernáculo português in GARRIDO, Álvaro-Barcos de Portugal - obras selecionadas de Octávio Lixa Filgueiras. Ílhavo: Câmara Municipal; Museu Marítimo, 2013, p. 7-15.

ROSAS, Lúcia Maria; BOTELHO, Maria Leonor e RESENDE, Nuno Ermida do Paiva: reflexões e problemáticas. Revista da Faculdade de Letras, Ciências e Técnicas do Património. Vol. XII (2013) 245-262.

SANTOS, Carla Sofia; SANTOS, Carla Alexandra e BALESTEROS, Carmen - Marcas de simbologia religiosa judaica e cristã ou cristã- 
-nova nos núcleos urbanos antigos de Estremoz e de Trancoso. Terrenos da Arqueologia da Península Ibérica - 3. ${ }^{\circ}$ Congresso de Arqueologia Peninsular - Actas, 1999. Porto: ADECAP, 2000, p. 207-228.

SANTOS, Marinho dos - Tradição e Modernidade com os Descobrimentos e a Expansão Portuguesa - Portugal, a Europa e o Mundo. Revista de História da Sociedade e da Cultura. 4 (2004) 89-103.

SERRÃO, Eduardo da Cunha e SERRÃO, Vitor Manuel - Vestígios da antiga capela do Espírito Santo dos Mareantes em Sesimbra. Jornadas Arqueológicas 3 - Actas, 1977. Lisboa, Vol. I, 1978, p. 387-407.

SOUTO, Juan - Marcas de cantero, graffiti y 'signos magicos' en el Mundo Islamico: panoramica general. Actes du Ve colloque International de glyptographie, I. Pontevedra, 1988, p. 463-486.

VILAÇA, Raquel - Considerações sobre cerâmica pré e proto-históricas do território português. Actas do Colóquio A produção de cerâmica em Portugal: Histórias com futuro. Museu de Olaria/Município de Barcelos, 2007, p. 7-26. 